\title{
ESCULTURAS EM BRONZE DA PRACCA CORONEL PEDRO OSÓRIO, PELOTAS, RS: UM DIAGNÓSTICO DO ESTADO DE CONSERVAÇÃO
}

\author{
Flávia Silva Faro \\ Mestranda PPG Memória Social e Patrimônio Cultural- UFPel \\ fsfgudixe@ hotmail.com \\ Profa. Dra. Margarete R. Freitas Gonçalves- UFPel \\ margareterfg@gmail.com
}

\begin{abstract}
RESUMO
O presente artigo aborda questões diretamente ligadas ao estado de conservação do patrimônio histórico e artístico que faz parte da cultura e da memória da cidade de Pelotas, no Rio Grande do Sul. Trata-se de uma parte da dissertação que estuda o estado de conservação das sete esculturas em bronze que além de serem trabalhos realizados por renomados artistas, elencam um conjunto de obras inseridas na Praça Coronel Pedro Osório, um dos locais mais relevantes do Centro Histórico da cidade. Neste contexto, as obras encontram-se em um estado de degradação que envolvem questões de ordem de envelhecimento natural e ações que não se justificam, como o vandalismo, fatores que influenciam na estética de cada uma, na apreciação in loco pelos transeuntes e degradação do patrimônio público.
\end{abstract}

Palavras - chave: escultura, bronze, Praça Coronel Pedro Osório, patrimônio.

\section{INTRODUÇÃO}

É visível e notório que hoje a cidade de Pelotas não é a mesma no tocante às suas construções e obras agregadas a estas. Suas características se transformaram, por diversas razões locais, como as ações dos que defendiam a modernização, em oposição aos que pregavam a valorização do antigo. Mas, o que ainda resta na cidade de hoje é uma herança da cidade de ontem devido a representatividade dos seus muitos casarões edificados no "estilo" eclético e suas praças. O ecletismo é um processo mais restrito e, embora possa ter origens políticas ou econômicas, manifesta-se antes como uma escolha pessoal que como uma necessidade histórica (READ, 2003, p.38). A história oficial da cidade de Pelotas se inicia em 1812, quando foi elevada à condição de Freguesia com a denominação de São Francisco de Paula. Em 1830, sob o mesmo título atingiu o status 
de Vila e, em 1835, passou a se chamar Pelotas (MAGALHÃES, 2011). Sua importância patrimonial e cultural, está atrelada à existência de casarões e seus elementos decorativos neoclássicos misturados ao gótico, remetendo a um ecletismo que embeleza a cidade. Além disso as charqueadas, os monumentos, os tesouros arqueológicos, e as suas tradições, elencam um conjunto de elementos evidenciados por riquezas artísticas e grande valor patrimonial. Alguns elementos decorativos representam verdadeiras obras de arte associadas às edificações, como pinturas murais, mosaicos, escaiolas, elementos de marcenaria, forros decorados, vitrais, esculturas e lustres, ou seja, bens culturais integrados que representam ressonância e significância social.

Dentre os espaços urbanos usufruídos pela comunidade pelotense, as praças que fazem parte do cotidiano, destaca-se a Praça Coronel Pedro Osório, assim chamada desde 1931. Não foi a primeira praça de Pelotas, mas é o mais relevante lugar do Centro Histórico da cidade, pois além de ser um espaço urbano representativo para os pelotenses e visitantes, devido a grande concentração de casarões em seu entorno ${ }^{1}$, de monumentos e esculturas que homenageiam pelotenses e beneméritos nacionais é, também, provida de uma arborização privilegiada. Esse espaço foi e ainda é cenário de encontros musicais, movimentações artísticas, feira do livro e diversas outras atividades onde o público interage e aprecia não só ações culturais, mas também a natureza e as obras que a compõe. De acordo com a Carta do Restauro de 1972, para efeito de identificação de centros históricos, leva-se em consideração, não apenas os antigos centros urbanos, assim tradicionalmente entendidos, como também de um modo geral todos os assentamentos humanos cujas estruturas unitárias ou fragmentárias ainda que se tenham transformado ao longo do tempo, tenham se constituído no passado, ou, entre muitos, os que eventualmente tenham adquirido um valor especial como testemunho histórico, ou características urbanísticas ou arquitetônicas particulares.

Entre alguns monumentos da Praça, destaca-se o conjunto de sete esculturas em bronze que foram analisadas in loco, através de exames organolépticos e registros fotográficos. Ainda foram realizados exames com extração de um corpo de prova e

\footnotetext{
${ }^{1}$ Antigo prédio do Banco do Brasil; Biblioteca Pública Municipal; Casa de Pompas Fúnebres Moreira Lopes; Casarão 2 (Secretaria Municipal da Cultura); Casarão 6; Casarão 8 (atual Museu do Doce); Casas geminadas 1 e 3; Clube Caixeral; Grande Hotel; Prefeitura Municipal; Quartel Legista (Casa da Banha) http://www.pelotas.com.br/pelotasturismo/atracoes-turisticas/pelotascultural/ < Acesso em 18 de abril de 2016>
} 
análises laboratoriais, as quais não estão incluídas neste artigo. Utilizou-se também de discussões interdisciplinares, ou seja, trabalhou-se com opiniões de diferentes áreas, fato que enriquece e solidifica o trabalho do conservador restaurador. Desta forma, fazem parte deste elenco, as seguintes obras: Monumento às Mães (1959); homenagem ao Dr. José Brusque Filho (1968); homenagem a Urbano Garcia; homenagem a Domingos José de Almeida; homenagem ao Dr. Francisco de Paula Amarante; homenagem ao Coronel Pedro Osório (1954) e Dr. Miguel Rodrigues Barcellos. Cabe salientar que as referidas obras são de autoria de renomados artistas, como: escultor gaúcho Antônio Caringi, o catalão Antônio Campins e o paulista Hildegardo Leão Veloso. Recentemente, mais precisamente em 16 de dezembro do ano de 2016, foi inaugurada a escultura de João Simões Lopes Neto, confeccionada pelo artista mineiro Léo Santana, a qual não faz parte deste contexto.

O valor cultural da Praça Coronel Pedro Osório, motivou a realização da presente pesquisa que se propõe a analisar o estado de conservação das esculturas em bronze existentes neste espaço, e seu continuo estado de degradação devido a exposição a fenômenos naturais físicos químicos que afetam o metal base, o bronze, e também a ação negligente de vândalos que resultam em lacunas, perda de informação e dissociação de partes.

\section{PRAÇAS COMO ESPAÇOS PÚBLICOS E INSTRUMENTO DE MEMÓRIA}

O espaço público na cidade assume inúmeras formas e tamanhos, compreendendo desde uma calçada até a paisagem vista de uma janela. Também abrange lugares designados ou projetados para usos cotidianos, cujas formas mais conhecidas são as ruas, as praças e os parques. Simultaneamente uma construção e um vazio, a praça não é apenas um espaço físico aberto, mas também um centro social integrado ao tecido urbano, e sua importância refere-se a seu valor histórico, bem como a sua participação continua na vida da cidade (ALEX, 2011, p.19). Portanto, procurar no espaço da cidade a visibilidade da sua história é buscar a memória. E a memória encontra-se na paisagem e no conjunto de tudo que descortina pessoas, instituições, arte, literatura, e que possa falar e construir a história desta cidade. Segundo Monquelat 
(2015, p.14), as praças são palco de manifestações artísticas e culturais de um povo que se altera com o passar do tempo e dos anos. Uma praça pública torna-se o suporte para inúmeros acontecimentos como: a perpetuação de nomes ilustres, fatos notáveis, acontecimentos memoráveis, encontros, desencontros, dramas, vandalismo e uma infinidade de outros fatos que são elencados para mostrar a competência e os cuidados ou não das administrações públicas para com essas. Na frase do teórico romano Cícero, "grande é a força da memória que reside no interior dos locais", segundo sua própria experiência, as impressões captadas em um cenário histórico são mais vivas que as assimiladas por ouvir falar ou pela leitura (ASSMANN, 2011, p.317- 318).

Sim, e ademais o uso que os olhos proporcionam e que te pode ser por si mesmo um guia até o saber. (...) Lá não pousarás teus pés em lugar algum, nem direcionarás teus olhos a lugar algum sem que te depares com algum monumento ou ganhes a recordação de algum antigo costume, alguma história antiga. (...) Quão grande e misteriosa é a alegria por uma visão como essa! Pois aqui não chegam somente o espírito, mas quase aos olhos, aquelas grandes personalidades, e pisamos o solo que elas vezes pisaram $^{2}$ (ASSMANN, 2011, p.329).

\section{A Praça Coronel Pedro Osório no contexto da cidade de Pelotas, RS.}

A Praça Coronel Pedro Osório é assim chamada desde $1931^{3}$ em homenagem póstuma ao Coronel Pedro Luís da Rocha Osório, falecido em 28 de fevereiro do mesmo ano. Embora não haja comprovação, alguns documentos indicam que inicialmente teve como primeiro nome, o de Praça do Teatro ${ }^{4}$. Em 1832 o seu nome mudou para Praça da Regeneração, em 1865 passou a ser chamada de Praça Dom Pedro II $^{5}$ e em 1895, chamou-se Praça da República, sendo também intitulada de Praça do Redondo, a partir da instalação do Chafariz Fonte das Nereidas, o qual segundo a ata da

\footnotetext{
${ }^{2}$ Em uma carta de 1578 escrita pelo humanista Justus Lipsio, o qual coloca muito precisamente seu ponto de vista ligado ao turismo de formação. (ASSMANN, 2011, p.329).

${ }^{3}$ LOPES, D. Simões. Reestruturação da Praça Cel. Pedro Osório como um conjunto urbano. Monografia apresentada no programa de Pós- graduação em Artes, como requisito parcial para obtenção do título em Especialista em Patrimônio Cultural: Conservação de artefatos, sob a orientação da professora mestre Carmem Lucia Abadie Biasoli ( 2005 p 70).

${ }_{5}^{4}$ As Praças de Pelotas e suas Histórias. A.F. Monquelat, 2015.

${ }^{5}$ Nome não muito aceito pela população, que manteve cotidianamente o nome Praça da Regeneração.
} 
Câmara Municipal recebeu autorização para ser instalado em 25 de junho de $1873^{6}$. De acordo com Monquelat, (2015, p.12) nossas praças tais como nossas ruas, desde muito tempo têm trocado de nome, inúmeras vezes. Antes de ser um jardim público, o terreno de 80 braças quadradas $^{7}$ de propriedade de Marina Eufrásia da Silveira ${ }^{8}$, cedido à Freguesia de São Francisco de Paula em 1827, funcionou como um pelourinho, onde os “criminosos", principalmente negros eram expostos e punidos.

Atos de destruição e furtos generalizados foram observados e relatados desde tempos passados, antes mesmo das esculturas em bronze já fazerem parte deste contexto. Segundo relato do "Jornal do Commercio, em janeiro de 1876 foram arrancados três bancos que guarneciam o centro da Praça Pedro II, bem como tentaram arrombar a casinhola que servia de abrigo ao guarda do chafariz. Em julho do mesmo ano segundo relato do jornal Diário de Pelotas ${ }^{9}$ deu-se início ao "arborizamento" da Praça Pedro II, que descrevia a importância desse melhoramento que tanto tinha de útil quanto de agradável, estava entregue à guarda do povo, e nele confiava o responsável por sua conservação (MONQUELAT, 2015, p.50-52).

Em meados de 1877 , a praça foi cercada ${ }^{10}$ com o objetivo de ficar protegida da ação de vândalos que costumavam agir no período da noite. Na ocasião, em seu entorno foi feito um gradeamento com pilastras de alvenaria e portões de ferro, o qual foi retirado por volta de 1917 (LOPES, 2005, p.26). Mesmo cercada, não deixou de ser alvo

\footnotetext{
${ }^{6}$ XAVIER, Janaina, Silva. Chafarizes e caixa D'água de Pelotas: Elementos de modernidade do primeiro sistema de abastecimento (1871). Monografia apresentada ao curso de Pós Graduação em Artes - Patrimônio Cultural e Conservação de Artefatos do Instituto de Artes e Design da Universidade Federal de Pelotas, como requisito parcial para obtenção do título de Especialista em Artes.

${ }^{7}$ Braça do latim brachia, plural de brachin (braço). Antiga unidade de medida de comprimento, equivalente a 10 palmos, ou seja, 2,2 cm. Braça também é unidade de comprimento do sistema inglês equivalente a cerca de 1,8 m. Braça quadrada (brasileiro), medida agrária que se usa no Mato Grosso, Mato Grosso do Sul, Sergipe, Alagoas: 3.0osso, Mato Grosso do Sul, Sergipe, Alagoas: $3.052 \mathrm{~m}^{2}(1$ braça $=2,2 \mathrm{~m})(30$ braças $=66 \mathrm{~m}) 30 \times 30$ braças $=4.356 \mathrm{~m}^{2}=$ braça quadrada. http://tecplanplanejamentos.com.br/pagina.asp?pagina=convermedidas <Acesso em 9 de maio de 2016>.

${ }^{8}$ Viúva do Terceiro Capitão mor de Rio Grande, Francisco Pires Casado, vinda de Portugal com mais algumas famílias, que aqui se estabeleceram no princípio do século XVIII. http://www.geocities.ws/escolamariana/histmariana/historiamariana.htm <Acesso em 03 de agosto de 2015>.

${ }^{9}$ Sem data.

${ }^{10}$ A pedido da sociedade pelotense (LOPES, 2005).
} 
de vandalismo, como demonstra a notícia publicada em primeiro de novembro de 1882 , o jornal Onze de Junho ${ }^{11}$ :

(...) por um desses atos de vandalismo que revelam a mais torpe ignorância e uma brutal malvadez, amanheceram mutiladas as estátuas que ornamentavam o centro da Praça Pedro II, as quais deveriam ser respeitadas, visto que ocupavam um lugar de honra cedido pela Câmara (MONQUELAT, 2015 p.94).

Como se pode constatar, a depredação de elementos que compõe o patrimônio público já fazia parte do contexto da cidade desde o século XIX. No século XXI, mais precisamente no ano de 2004, algumas ações de depredações foram registradas em fichas cadastrais sob cuidados da Secretaria Municipal de Cultura de Pelotas, Secult, nas quais constam informações de furto de ornatos e vandalismo nos monumentos já patrimonializados da praça ${ }^{12}$.

De acordo com Dvorak (2008, p.70-71), em primeiro lugar são as obras de arte e sua expressão visual que unem presente e passado no plano do sentimento e na fantasia, desta forma, quem destrói tais monumentos é um inimigo de sua cidade e de seu país e prejudica a comunidade, pois as obras de arte públicas não foram criadas para esse ou aquele indivíduo, e aquilo que elas encarnam enquanto obras de arte, fascínio pictórico, recordações ou qualquer outro sentimento, é um patrimônio comparável às criações dos grandes poetas ou às realizações da ciência.

A proteção dos bens culturais existentes nas praças gera um processo de identificação entre a cidade e a sua população a partir do surgimento da responsabilidade coletiva em protegê-las e conservá-las, bem como tornar viável que gerações futuras tenham acesso à parte da memória de sua comunidade.

\footnotetext{
${ }^{11}$ Jornal pelotense do final de 1882 .

www.cmu.unicamp.br/seer/index.php/resgate/article/download/../252 <Acesso em 0708/2015>.

${ }^{12}$ Esculturas em bronze e outros monumentos com : relógio solar, homenagem a Iolanda Pereira (Miss Universo, 1930), e outros.
} 


\section{ESCULTURAS EM BRONZE DA PRAÇA CORONEL PEDRO OSÓRIO}

As sete esculturas em bronze da Praça Coronel Pedro Osório são homenagens a personalidades que fizeram parte da história da cidade de Pelotas. Cada uma com seu estilo e técnica, as esculturas foram confeccionadas por três renomados artistas, Antonio Caringi, Antonio Campins e Hildegardo Leão Veloso, e encontram-se localizadas como ilustra a planta esquemática (Figura 1). Representam monumentos históricos, no que se refere às homenagens a beneméritos que de alguma forma contribuíram para o desenvolvimento e crescimento da cidade e também representam monumentos artísticos que por sua qualidade de produção, já embelezaram a praça, visto que hoje encontramse sem conservação. Cabe salientar que através das observações in loco, notou-se que as ações de vandalismo são mais representativas em obras com adornos, flores de acanto, e saliências.

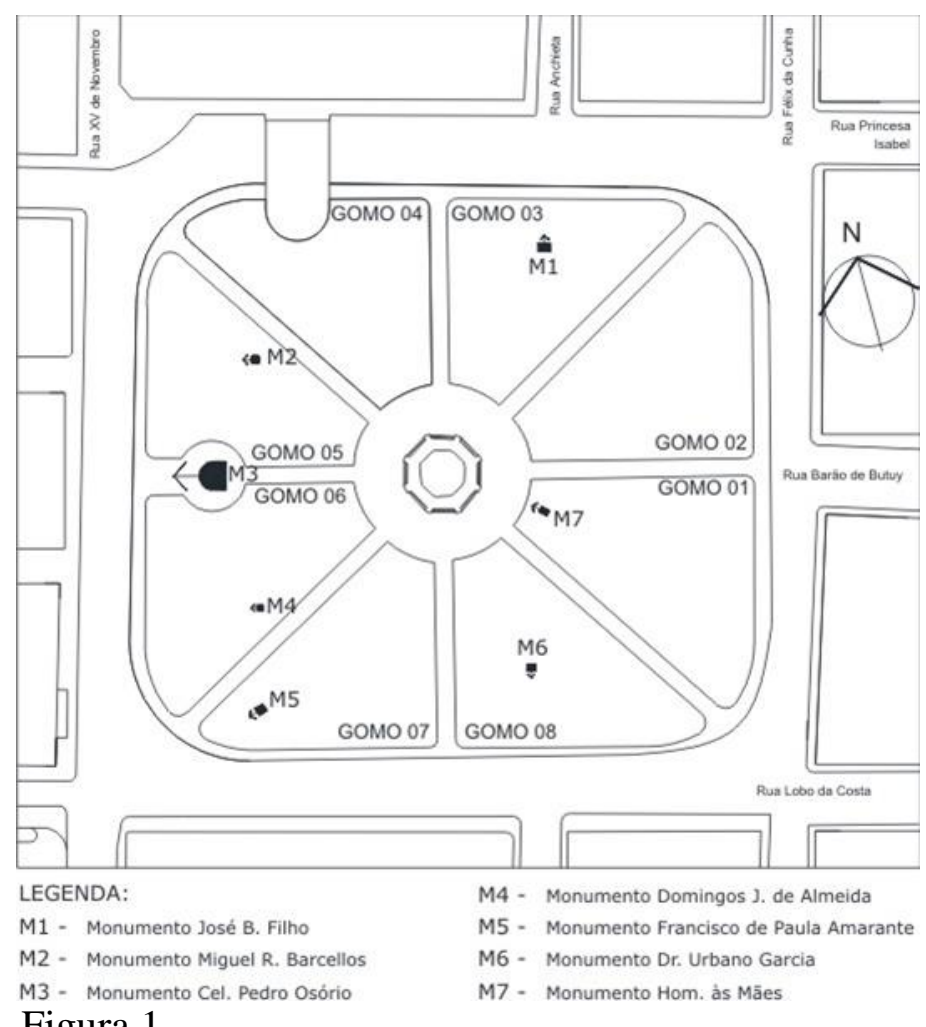

Figura 1

Figura 1: Localização das esculturas na praça em planta esquemática. A letra "M" representa monumento, gomo representa a subdivisão dos quadrantes em gomos, e a seta indica a posição frontal de cada obra. Fonte: Jeferson Sallaberry, Pelotas, 2015. 
Compõem o conjunto das esculturas :

Escultura em homenagem às Mães 1959 (GOMO 01, M7) (Figuras 2 e 3), obra do escultor Antônio Caringi, com os seguintes dizeres em placa frontal: "Este monumento às mães teve como modelo a poeta Noemi de Assupção Osório Caringi, esposa do escultuor Antônio Caringi”. Observou-se que abaixo da atual placa no pedestal, há vestígios de uma possível placa original ou troca de posição. Hoje restam apenas os furos indicando o local de origem da placa. Esta obra pode ser considerada como a mais conservada de acordo com exames organolépticos realizados. O bronze encontra-se em ótimas condições. Este aspecto pode ser decorrente do acabamento aplicado pelo artista, localização da obra em relação à posição solar, a própria umidade ocasionada pelo fechamento da copa das árvores, ou seja, a obra não está localizada em ponto de maior quantidade de vegetação. Foi observada a falta de um adorno (tartaruga) perto dos pés da criança (Figuras 4 e 5), esta observação foi feita através da comparação entre fotos e confirmação in loco. Há uma outra obra em homenagem às mães na cidade de Alegrete com a representação feminina em posição ereta segurando as mãos da criança para cima, o artista fez também de modelo sua esposa.

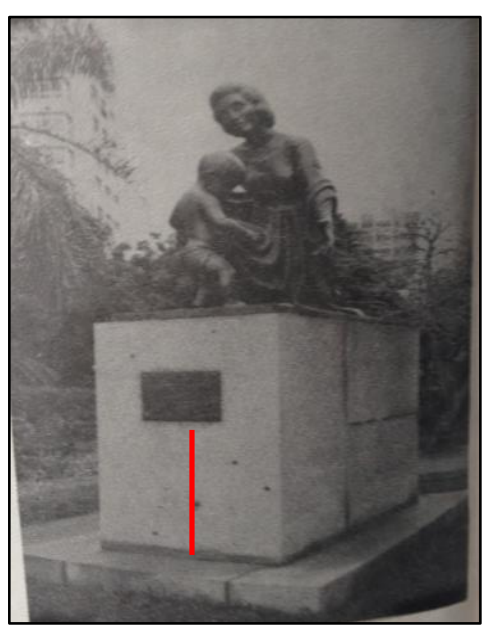

Figura 2

Figura 2: Homenagem às Mães, placa na posição original. Fonte: Eturfpel / Enfoke.

Guia Turistico de Pelotas 1984.

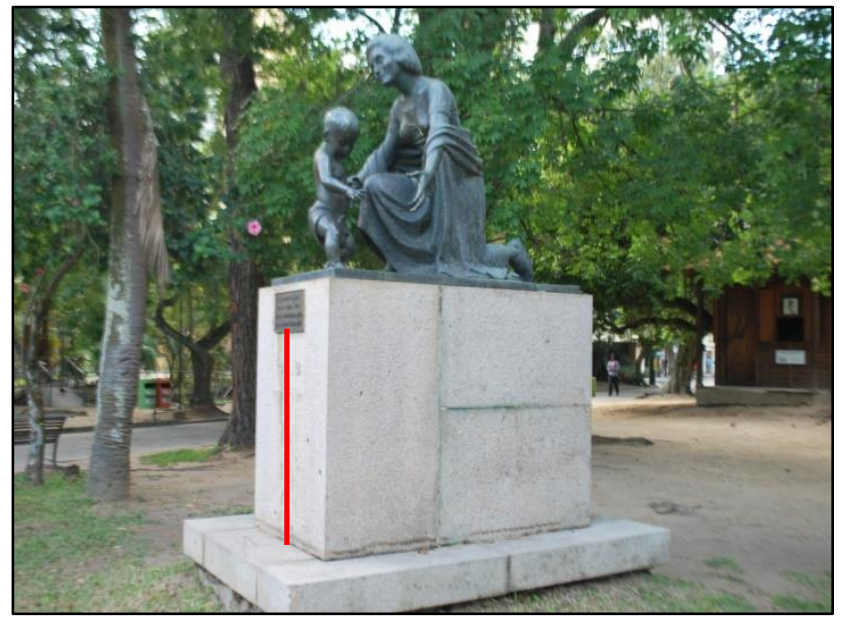

Figura 3

Figura 3: foto atual com deslocamento Frontal. Fonte: Flávia Silva Faro, 2015. 


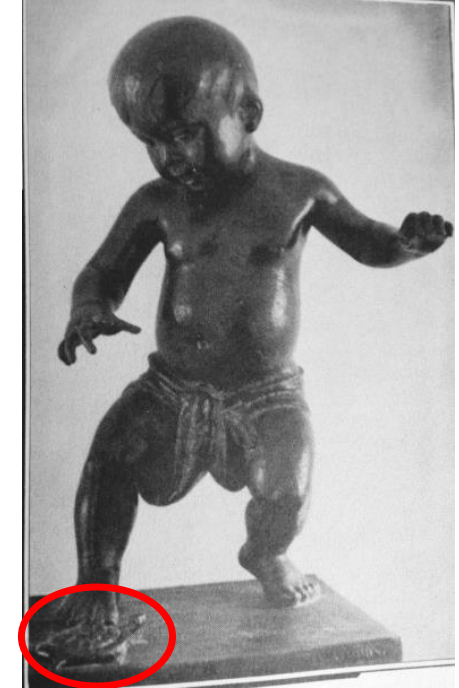

Figura 4

Figura 4: mostra a criança olhando em direção à tartaruga. Fonte: PAIXÃO, Antonina. A escultura de Antonio Caringi. Conhecimento, técnica e arte. Pelotas: Ed. UFPel, 1988.

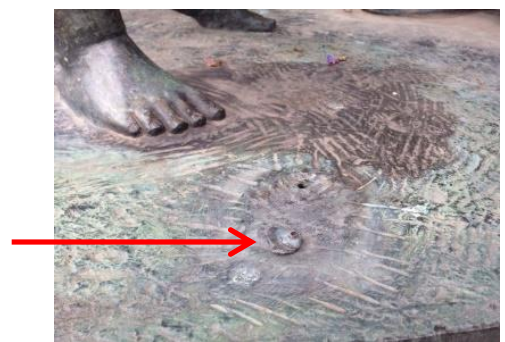

Figura 5

Figura 5: A laguna, espaço sem o adorno (tartaruga). Fonte: Flávia Silva Faro, 2016.

Escultura do Dr. José Brusque Filho, 1968 (GOMO 03, M1), (Figuras 6 e 7) obra do escultor Antônio Caringi, contém os seguintes dizeres entalhados no granito: "Exerceu a medicina, praticou a caridade e mereceu a gratidão dos pósteros. 1962”. Atualmente encontra-se sem o relevo frontal de bronze restando somente as marcas dos furos na pedra, que ainda fazia parte da obra até outubro de $2006^{13}$. Também encontra-se sem o símbolo do curso da medicina ${ }^{14}$, o caduceu, que estava aos cuidados da Secretaria

\footnotetext{
${ }^{13}$ Observado por registro fotográfico. MUTZENBERG, Lenice, Lucia. A Escultura pública de Antonio Caringi em Pelotas.Monografia apresentada ao Curso de Pós- Graduação em ArtesEspecialização em Patrimônio Cultural: Conservação de Artefatos do Instituto de Artes e Design da Universidade Federal de Pelotas, como requisito parcial à obtenção de titulo de Especialista em Patrimônio Cultural: Conservação de Artefatos. ( 2006, p.47).

${ }^{14}$ Símbolo que se encontra sob cuidados da Secretaria da Cultura, Secult de Pelotas. O símbolo da medicina é representado pelo Bastão de Asclépio (ou Esculápio), o qual consiste em um bastão, varinha ou haste, com uma cobra entrelaçada. Na mitologia grega antiga Asclépio é o deus da cicatrização, ou da própria medicina. Dada a capacidade de trocar de pele, a cobra constante no símbolo representa o renascimento, bem como a fertilidade. $O$ bastão, por sua vez, é um símbolo de autoridade. Ele representa o poder divino, a quem, apesar dos esforços e habilidades médicas, cabe decidir sobre a vida ou a morte de alguém. O caduceu é um símbolo astrológico ligado ao deus grego Hermes, que com frequência é encontrado como representação da Medicina. Essa ideia surge a partir do século VII quando o caduceu associouse à alquimia. Por esse motivo, ele permanece até hoje como um símbolo representativo da prática farmacêutica e, em decorrência, da medicina.
} 
Municipal da Cultura, e foi cedido para análise desta pesquisa. Este ornato tem sessenta centímetros de altura e pesa aproximadamente $5 \mathrm{~kg}$. (Figura 8). A obra apresenta uma lacuna significativa, quatro dedos da mão esquerda (indicador, médio, anelar e mínimo) depredados, provavelmente por ação criminosa de vândalos (Figura 9).

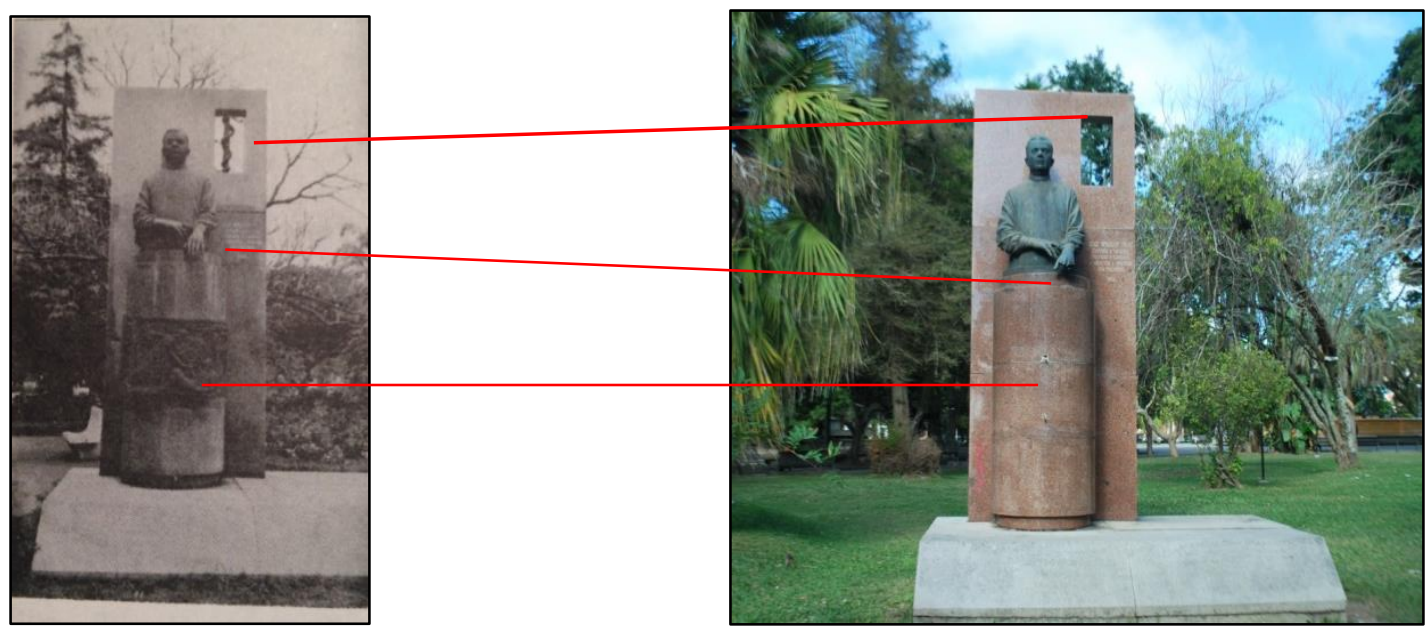

Figura 6

Figura 7

Figura 6: José Brusque Filho ainda com adornos e dedos

Figura 7: Foto atual com lacunas e dissociação de partes. da mão esquerda. Fonte: Fonte : Flávia Silva Faro, 2016. Eturfpel / Enfoke. Guia Turistico de Pelotas. 1984.

http://www.dicionariodesimbolos.com.br/simbolo-medicina/ <Acesso em 29 de agosto de 2016>. 


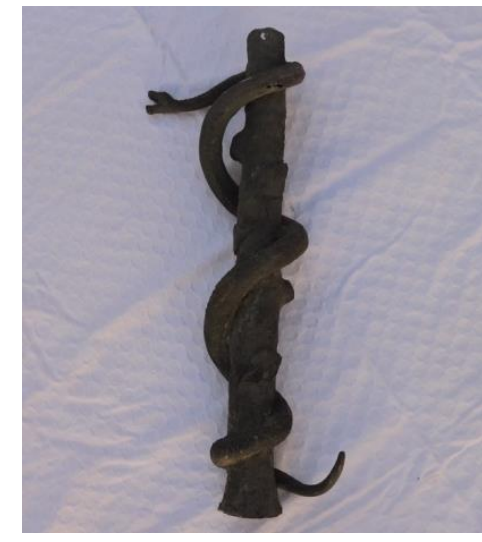

Figura 8

Figura 8: O caduceu cedido pela Secretaria Municipal da Cultura. Fonte : Flávia Silva Faro. 2016

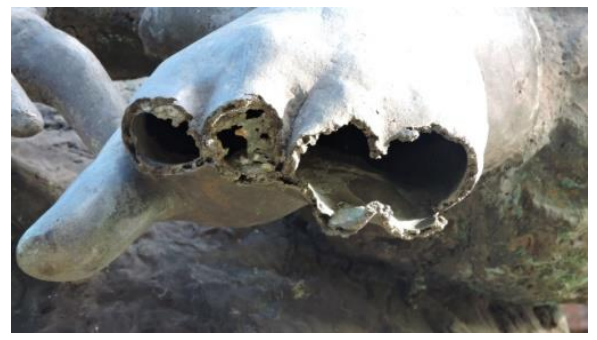

Figura 9

Figura 9: Lacuna significativa na mão esquerda. Fonte: Gabriel Faro, 2016.

Busto (herma) do Dr. Francisco de Paula Amarante (Gomo 07, M5) ( Figuras 10 e 11) é uma obra do escultor Antônio Caringi, na qual consta em um placa de bronze frontal os seguintes dizeres: "Preito de gratidão ao Dr. Francisco de Paula Amarante "Há um único meio de vencer a morte: é a consciência de ter feito o bem. 1950”. Uma das características das obras de Caringi, é a proporção entre obra e pedestal, ou seja, o busto não se sobressai ao pedestal, nem vice e versa. Tanto a placa em bronze quanto o busto (Figura 12) encontram-se com manchas esverdeadas e esbranquiçadas, que podem ser ocasionadas por razões climáticas ou de origem animal. 


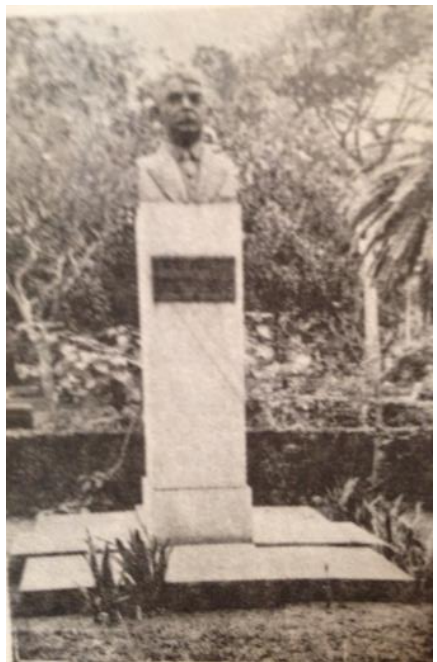

Figura 10

Figura 10: Sem alterações aparentemente significativas. Fonte: Eturfpel / Enfoke. Guia Turistico de Pelotas. 1984 .

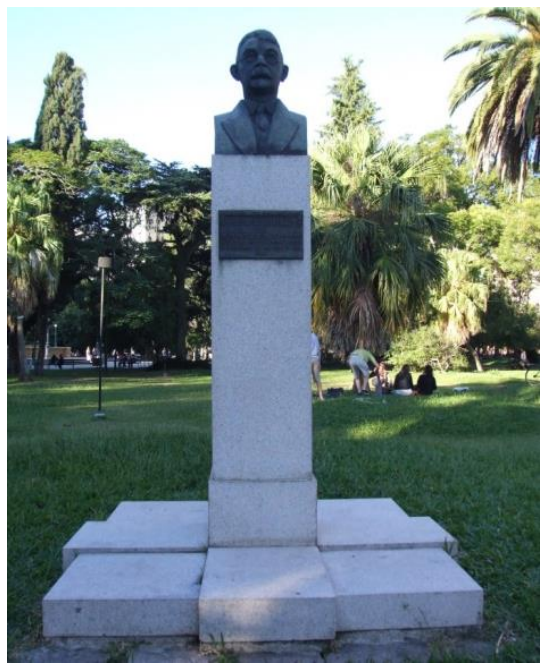

Figura 11

Figura 11: Foto atual. Fonte: Flávia Silva Faro, 2015.

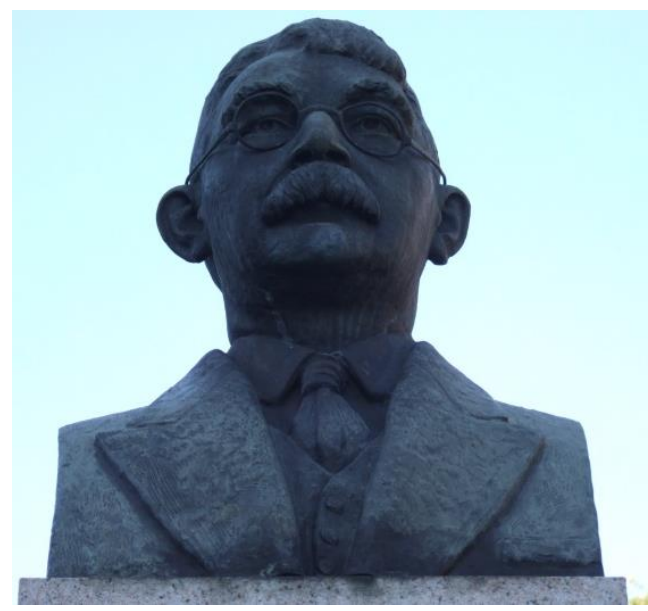

Figura 12

Figura 12: Manchas esverdeadas, esbranquiçadas e escorridos. Fonte: Flávia Silva Faro, 2015. 
A escultura Coronel Pedro Osório (Gomos 5 e 6, M3) (Figuras13 e 14 ) é uma obra do escultor Antônio Caringi, feita para homenagear seu centenário. Contém os seguintes dizeres: “Ao Cel. Pedro Osório 1854 - 1954”. A escultura encontra-se com coloração esverdeada e manchas, não foi atingida pelo vandalismo, visto que se encontra a uma altura de mais ou menos 5 a $6 \mathrm{~m}$. O pedestal desta escultura é alvo frequente de pichações, atualmente sua parte posterior encontra-se pichada com assinaturas (Figura 15) símbolos e letras, na parte frontal encontram-se pichações políticas. É um dos pedestais mais atingidos por pichações e também o maior deles. Há um relevo em bronze na parte frontal do pedestal com representações da pecuária e desenvolvimento econômico da cidade de pelotas, na parte posterior do pedestal, também esculpida por Antonio Caringi na pedra, a representação das Três Idades do Trabalho.

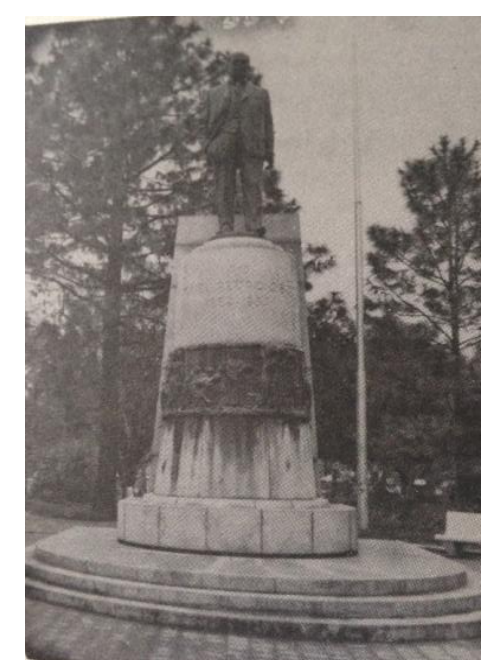

Figura 13

Figura13: Homenagem ao Coronel Pedro Osório. Fonte: Eturfpel / Enfoke. Guia Turístico de Pelotas, 1984.

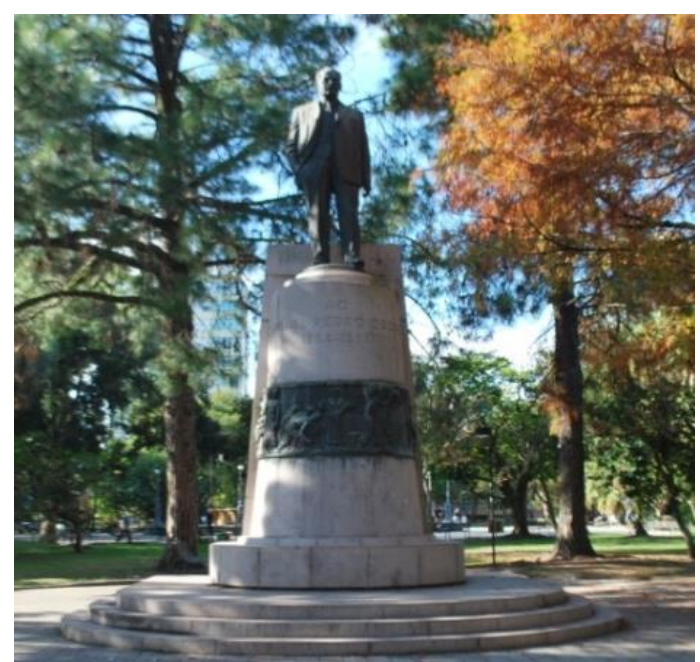

Figura 14

Figura 14: Imagem atual. Fonte : Flávia Silva Faro, 2015 


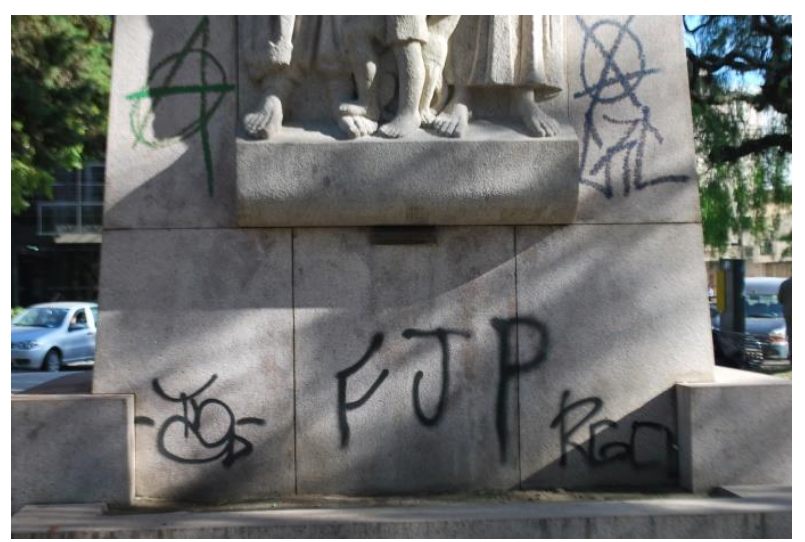

Figura 15

Figura 15: Parte posterior do pedestal com pichações. Fonte: Flávia Silva Faro, 2016.

A escultura em homenagem ao Dr. Urbano Garcia, (GOMO 08, M6) ( Figuras 16 e 17), trata-se de uma obra do artista paulista Hildegardo Leão Veloso com os seguintes dizeres desgastados, em baixo relevo, gravado no granito: “Dr. Urbano Garcia. Foi inexcedivel em caracter, em civismo, em bondade. Ninguém o excederá na saudade e na gratidão de seus conterrâneos. Atualmente a obra encontra-se sem marcas de vandalismo, com coloração esverdeada que pode ser considerada uma pátina de envelhecimento, alguns pontos apresentam cor esbranquiçadas. O relevo embutido na pedra apresenta as mesmas características do busto em relação à coloração (Figura 18).

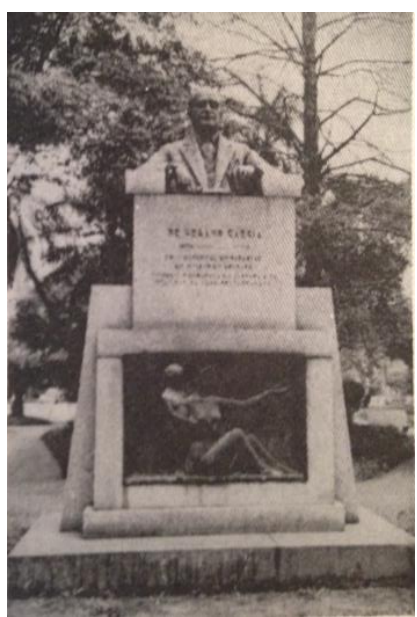

Figura 16

Figura 16: Homenagem ao Dr. Urbano

Garcia.Fonte: Eturfpel / Enfoke.

Guia Turistico de Pelotas, 1984.

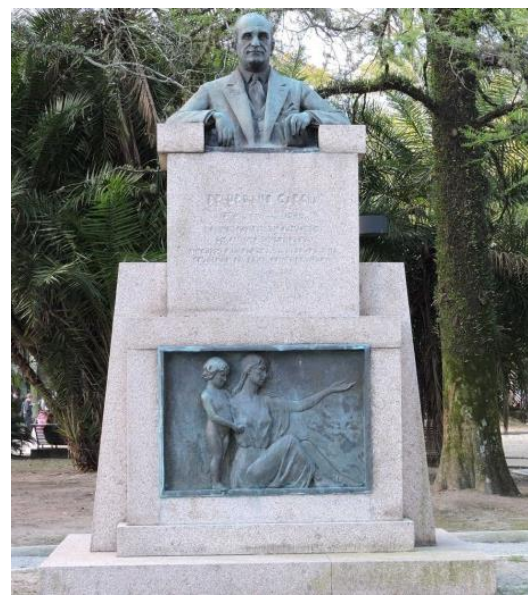

Figura 17

Figura 17: Foto atual da obra, observa-se uma pátina de envelhecimento. Fonte: Flávia Silva Faro, 2015. 


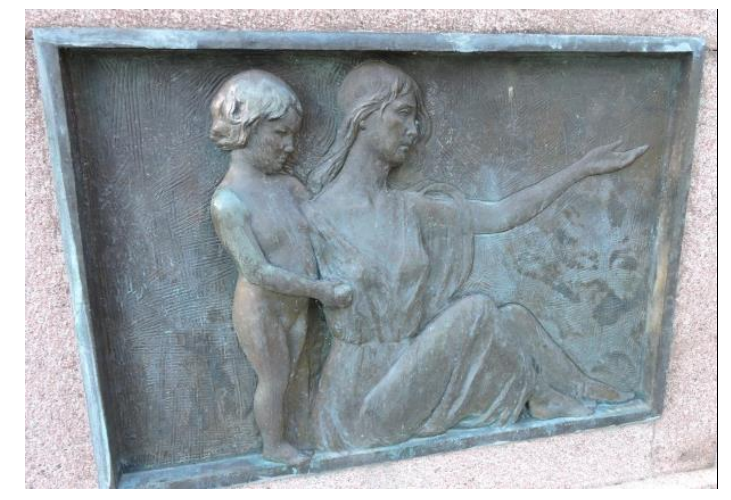

Figura 18

Figura 18: relevo em bronze da obra em homenagem ao Dr. Urbano Garcia, com tom esverdeado e manchas esverdeadas. Fonte: Flávia Silva Faro, 2016.

A escultura de Domingos José de Almeida (GOMO 06, M4) (Figura 19 e 20) é uma obra do artista catalão Antonio Campins que contém os seguintes dizeres em uma placa de bronze frontal: "Domingos José de Almeida. Delineador desta cidade a que deu o nome. Benemérito obreiro do progresso local. Homenagem do Município de Pelotas”, encontra-se com seu pedestal de alvenaria forrado com placas de mármore depredado como resultado dos adornos em bronze furtados. Na (Figura 19) os oito adornos em bronze, quatro superiores e quatro inferiores, ainda faziam parte do pedestal que compõe o conjunto da obra. Em virtude do furto dos adornos, o pedestal em pedra está comprometido, alguns dizeres gravados na pedra estão incompletos (dissociação de informações), há muitos arranhões aparentemente feitos com objeto pontiagudo também em cima dos dizeres que ainda permanecem (Figura 21). Na parte posterior do busto, há manchas escorridas e esbranquiçadas (Figura 22), o tom esverdeado permanece na maior parte da obra. Há vestígios de intervenção anterior no pedestal, acredita-se que com o objetivo de fixação de algumas pedras que porventura estariam soltas. 


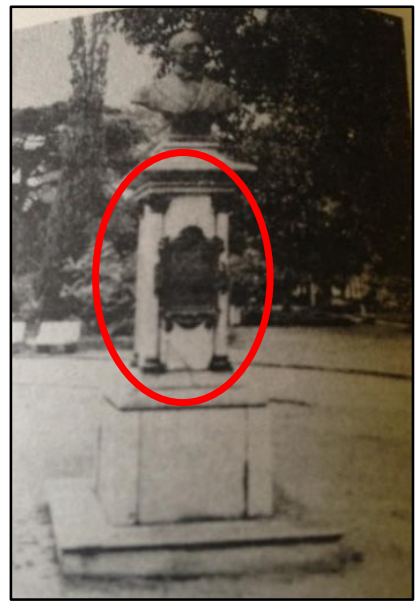

Figura 19

Figura 19: Escultura com os adornos, vista frontal. Fonte: Eturfpel / Enfoke. Guia Turístico de Pelotas, 1984.

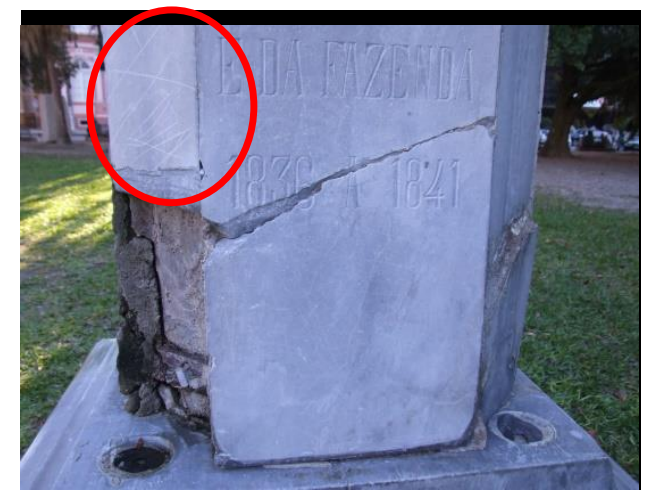

Figura 21

Figura 21: Pedestal comprometido pelo furto dos adornos e arranhões feitos com objeto pontiagudo. Fonte : Flávia Silva Faro, 2015.

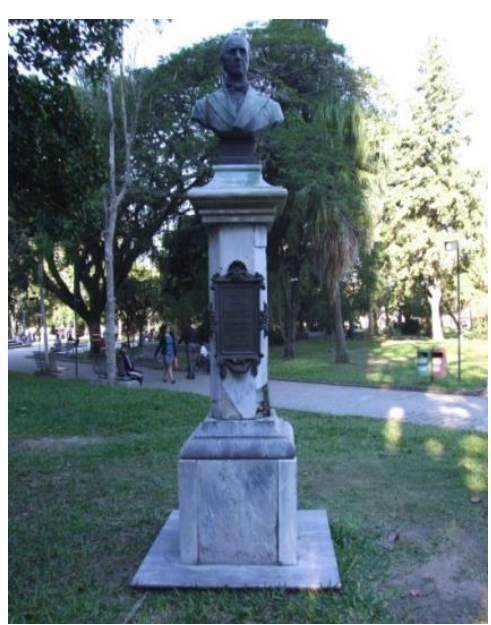

Figura 20

Figura 20: Foto atual sem adornos em bronze.

Fonte: Flávia Silva Faro, 2015.

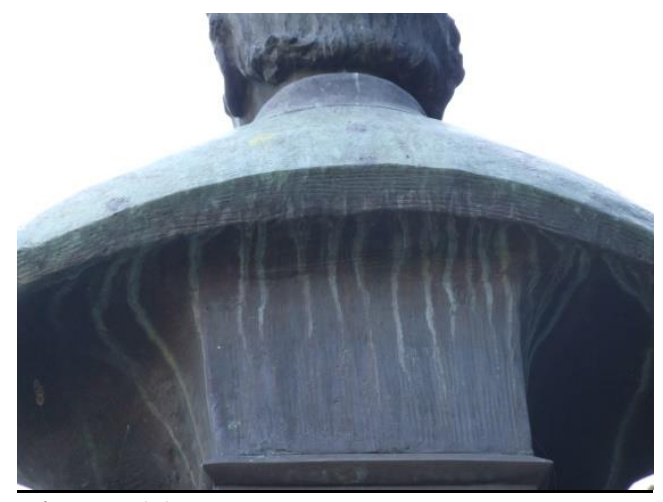

Figura 22

Figura 22: Manchas escorridas na parte posterior do busto.

Fonte: Flávia Silva Faro, 2015.

A escultura do Dr. Miguel Rodrigues Barcellos (Gomo 05, M2) ( Figuras 23 e 24) outra obra do artista Antonio Campins, que contém os seguintes dizeres em um placa de bronze frontal: "Dr. Miguel Rodrigues Barcellos, Barão de Itapitocay, gratidão do povo de Pelotas “o pae dos pobres" 1913”. Seu pedestal em pedra encontra-se sem 
dois adornos inferiores em bronze, um frontal, o outro lateral (Figura 25) e sua base encontra-se com uma patologia provavelmente causada por infiltração decorrente da dissociação do adorno. Há muitas sujidades principalmente na região do peito e olhos (Figura 26). Este acúmulo de sujidades pode se tornar propício ao acúmulo de umidade , podendo ocasionar pontos de corrosão.

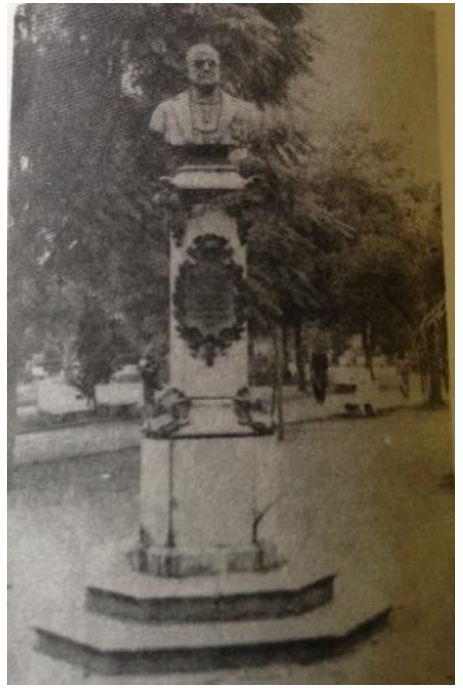

Figura 23

Figura 23: Homenagem ao Dr. Miguel Rodrigues Barcellos, obra ainda com os adornos em bronze. Fonte: Eturfpel / Enfoke.

Guia Turístico de Pelotas, 1984.

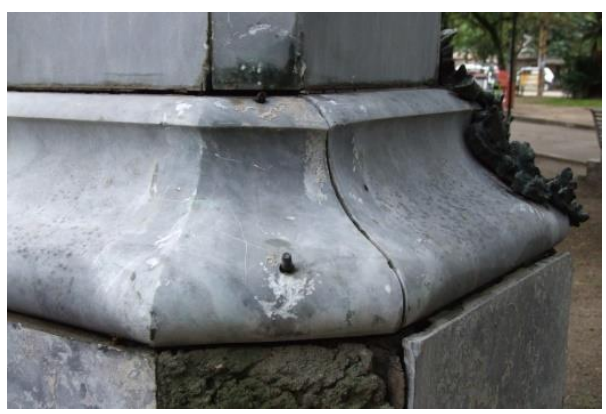

Figura 25

Figura 25:Ppedestal sem o adorno. Fonte: Flávia Silva Faro, 2016.

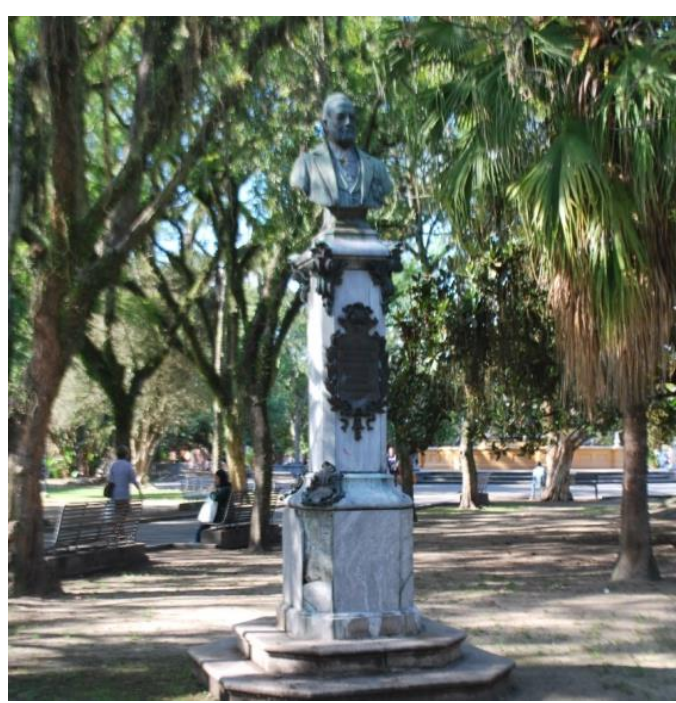

Figura 24

Figura 24: Foto atual da obra sem os dois adornos inferiores.

Fonte: Flávia Silva Faro, 2015.

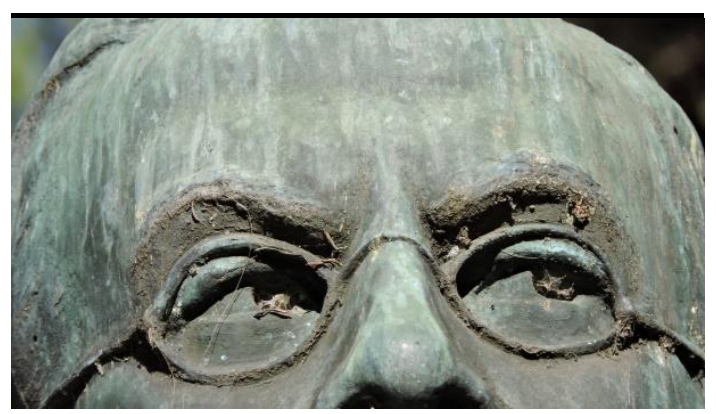

Figura 26

Figura 26: Acumulo de sujidades na região do olhos.

Fonte : Flávia Silva Faro, 2016. 


\section{Considerações sobre os artistas}

Sobre os artistas envolvidos na produção das esculturas em questão, Antonio Caringi envolve o maior numero de informações a respeito de técnicas e estilos. Nascido em 18 de maio de 1905 em Pelotas, e falecido em 1980 nesta cidade, representou em suas obras características as vezes simples e outras severas, mas todas ricas em expressão e sentimento. Estudou com Arno Brecker ${ }^{15}$, especializando-se em plástica monumental. Depois de quatorze anos aproximadamente no Velho Mundo, o escultor pelotense retorna ao Brasil em janeiro de 1940 onde casa-se com a poetisa Noemy Assumpção Osório, modelo que o inspirou para a escultura "Homenagem às mães”. Produziu aproximadamente 128 obras entre estatuetas, monumentos, medalhões, cabeças, maquetes. Foi um artista de grande talento e prestígio sendo um dos escultores mais premiados do Rio Grande do Sul (MUTZENBERG, 2006, p.21). Em 1952 cria o curso de escultura na Escola de Belas Artes de Pelotas.

A busca do estilo próprio leva o artista pelotense a percorrer um caminho que tem início na experiência vivida e adquirida pelo estudo e comparação de obras do passado. Caringi assimilou formas e técnicas diversas e criou suas próprias formas aplicando técnicas de acordo com a maneira particular de expressão, sendo a figura humana o tema preferido do escultor. O volume de suas obras nem sempre é maciço, a maior parte das obras são ocas. De acordo com Caringi: "Quanto mais fino é o bronze, melhor se torna a fundição", e a respeito do volume, o escultor diz: " deve estar tudo ali num bloco cuja unidade seja indissolúvel"(PAIXÃO, 1988, p.49). Modelava suas formas primeiro em argila, depois passava para formas em gesso, que o artista considerava como um instrumento passageiro da matéria definitiva, para finalmente fundi-las em bronze. Em relação à fundição Caringi enfatizava a necessidade de uma assistência do artista à mesma. Quanto à textura, seguiu o exemplo de seus mestres: "falavam que a escultura não deveria ser lisa assim como sabão" (PAIXÃO, 1988, p.54). Quanto ao pedestal, este deve ter uma harmonia e proporção com a obra, geralmente utilizava-se do granito ou mármore. Em todos os seus trabalhos são encontrados unidade, variedade, ritmo, harmonia, contrastes, equilíbrio e proporção.

\footnotetext{
${ }^{15}$ Escultor preferido de Hitler (PAIXÃO, 1988, p.21)
} 
Sobre Antonio Campins a observação de seu nome na obra em homenagem ao Dr. Domingos José de Almeida (Figura27) e na base do pedestal da obra de Miguel Rodrigues Barcellos (Figura 28), remete á ideia de que é o escultor. Dados encontrados citam Antonio Campins como sócio da firma de fundição em Barcelona Masriera em 1896, passando a ser chamada Masriera y Campins.

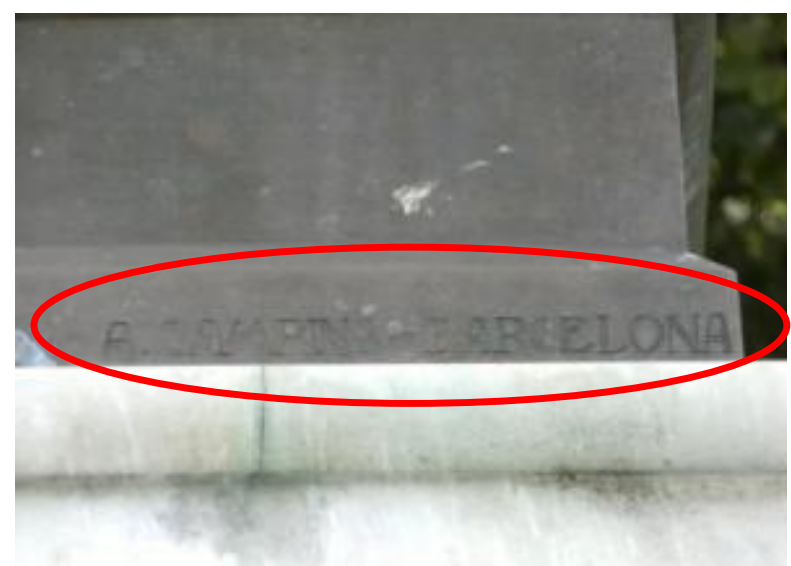

Figura 27

Figura 27: descrição A. Campins Barcelona homenagem ao Dr. Domingos José de Almeida.

Foto: Claudia Lacerda, 2010.

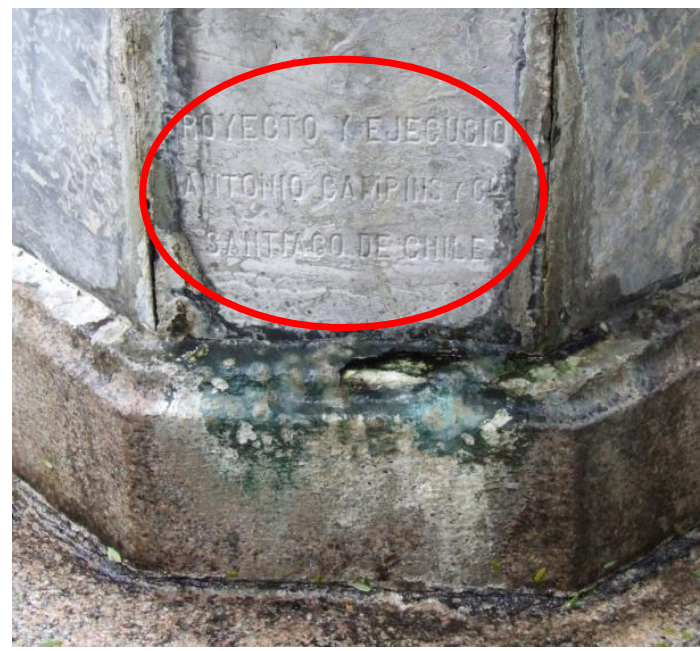

Figura 28

Figura 28: base do pedestal gravado "Proyecto y ejecucion Antonio Campins, y Cia Santiago do Chile", homenagem a Miguel Rodrigues Barcellos.

Foto: Flávia Silva Faro, 2015. 
Hildegardo Leão Veloso, autor da escultura em homenagem ao Dr. Urbano Garcia, nasceu em Palmeiras, SP em 1899 e morreu em 1966 no Rio de Janeiro. De suas obras destacam-se o monumentos ao Almirante Marquês de Tamandaré na paria de Botafogo no Rio de Janeiro e Getúlio Vargas em Laguna SC. Embora suas obras não apresentem traços do modernismo, participou da Semana de Arte Moderna de 1922. Foi autor da estátua equestre do General Osório em homenagem ao Patrono da Cavalaria pelo Exército Brasileiro, inaugurada na Praça da Alfândega em Porto Alegre em 7 de agosto de 1933. Exerceu livre docência na cadeira de escultura na antiga Escola de Belas Artes a partir de 1950, assinava suas obras : H. Leão Veloso ${ }^{16}$.

\section{DEGRADAÇÃO DOS METAIS}

Os metais se caracterizam por sua rápida interação com o meio onde encontramse expostos, visto que em contato como ar atmosférico uma série de reações cinéticas e sinérgicas ocorrem. Essa interação resulta de uma série de reações químicas de oxidação e redução, muitas delas com elevada ação degenerativa como por exemplo a corrosão (MARTINEZ; ALONSO, 2011, p.38-41).

Além da corrosão, o manuseio e armazenagem inadequados, são as principais causas dos danos aos artefatos metálicos e não menos importante desde tempos remotos inclui-se também nestas causas o vandalismo. Um deficiente manuseio pode acarretar uma série de problemas irreversíveis e desta forma a perda de valor atribuído à obra. Pode causar fraturas, empenamentos, fissuras e partes amassadas. Deve-se levar em consideração que os sais, as gorduras e a umidade podem provocar o desenvolvimento de corrosão e de manchas nas ligas de cobre, por isso um manuseio com luvas torna-se impreterivelmente adequado tanto para obras de acervo quanto para bronzes de exterior.

A corrosão nas ligas de cobre progride quando há uma elevação na umidade relativa do ar, ou seja, acima de $70 \%^{17}$. A cidade de Pelotas, por exemplo, chega a atingir quase $100 \%$ de umidade relativa do ar no inverno e verão muitas vezes com

\footnotetext{
${ }^{16} \mathrm{http}: / /$ karlynh.blogspot.com.br/ <Acesso em 13 de abril de 2016.>

${ }_{17}$ Tratamento e conservação de Latão e Bronze Históricos. Henry Ford Museum \& Greenfield Village. http://www.hfmgv.org/research/cis/brass.html. < Acesso em 12 de setembro de 2016.>
} 
variações muito bruscas ${ }^{18}$. Porém, para a maioria do metais a umidade relativa do ar mais baixa em atmosfera muito poluída pode também ser muito crítica, visto que o acumulo de pó e fuligem nas obras são partículas que acabam retendo a umidade e induzido à corrosão.

As esculturas de bronze fundido são constituídas por ligas de cobre, em geral pela liga $\mathrm{Cu}-\mathrm{Sn}-\mathrm{Zn}$, nas quantidades de $90 \%$ de cobre, $6 \%$ de estanho e $4 \%$ de zinco ${ }^{19}$. Se forem devidamente cuidadas as ligas de cobre são materiais relativamente estáveis e resistentes à corrosão.

Nas obras localizadas em espaços externos, as alterações da liga metálica são mais intensas devido a maior interação induzida pelo meio que resulta em superfícies mais porosas sujeitas a uma maior absorção e acúmulo de umidade, ocasionando a corrosão.

Em termos de aspecto superficial dos metais a pátina é uma cobertura homogênea formada na superfície e percebida como resultado dos processos naturais, antrópicos e do passar do tempo, variando a cor desde o verde claro ao castanho escuro de acordo com a origem da liga. Mas, concretamente, a origem das pátinas metálicas é atribuída aos tratamentos de proteção que se aplicava de maneira rotineira na antiguidade para proteger e igualar as superfícies, e que se combinavam com as reações físico químicas entre o metal e o meio ambiente, os processos biológicos e o envelhecimento natural (MARTÍNEZ; ALONSO, 2011, p. 13). . Para o escultor Antonio Caringi, a cor do bronze é característica e o trabalho fundido não deve levar nenhuma pátina. "A cor do bronze é esta aqui, dourada, ouro". Apenas convencionou-se para não manchar ,banhar o trabalho com ácido, antimônio ou sulfureto de cobre, para desafiar as marcas do tempo (PAIXÃO, 1988, p.57). As pátinas têm um valor estético quando são estáveis. Servem para ocultar elementos destoantes dos processos de fabricação como: manchas, juntas etc, embelezando a obra. Apresentam um valor funcional, protegendo os metais da agressão do meio em que se encontra, e um valor científico visto que transmitem uma ampla informação a nível artístico de caracterização de material e a nível sensorial contribuindo para sua autenticidade. A pátina verde oferece um acabamento atraente como pode ser visto na Estátua da Liberdade em Nova York, que é revestida pela pátina do cobre oxidado na estrutura de aço (ASKELAND, 2008, p.431).

\footnotetext{
${ }^{18}$ Observações por termohigromêtro digital . Fontes da autora.

${ }^{19} \mathrm{https} / / / 5$ cidade.files.wordpress.com/2008/05/tratamento-e-conservacao-de-latao-e-bronzehistoricos.pdf <Acesso em 18/04/2016>
} 


\section{CONCLUSÃO}

O reconhecimento e observação da obra a ser estudada, conservada ou restaurada, é de grande interesse de caráter arqueológico, histórico e artístico, na medida que possibilita nexos entre a procedência, tecnologia dos materiais e as técnicas de fabricação. As transformações ocorridas na sociedade geram também um processo constante de modificações culturais. Os pensamentos sobre conservação e restauração vêm acompanhando estas mudanças e simultaneamente evoluindo no que diz respeito aos conceitos e critérios. Cada vez torna-se mais importante a presença e participação de profissionais de outras áreas que complementam um diagnóstico.

O passado forneceu o alicerce para uma compreensão de conceitos e ideia de patrimônio, conservação e restauração da atualidade. Melhor conservar para não restaurar, mas se preciso for que utilize-se a técnica baseada na teoria que melhor se adapte ao conjunto da obra, ou seja, o embasamento teórico para a atividade de conservação de bens culturais é fundamental para seu melhor exercício prático. O parecer técnico e o procedimento prático tornam-se únicos para cada bem material. O profissional jamais pode generalizar sua maneira de atuação e suas decisões, as quais devem respeitar os critérios de mínima intervenção. Cada obra deve ser estudada e analisada individualmente quanto às suas necessidades de preservação, respeitando sempre a sua história passada, presente e futura, sua estética, sua integridade física e, não menos importante, seus sujeitos, visto que as questões relativas à conservação-restauração não são simples nem tampouco passíveis de soluções generalistas, pois envolvem uma complexa rede de princípios, critérios, escolhas e saberes (CALDAS, 2011).

Para conservar um objeto é necessário primeiramente identificá-lo, processo muitas vezes dificultado quando se trata de artefatos culturais pela diversidade histórica, geográfica e temporal de processos e materiais que os compõem, o que os torna exemplares únicos. Aliada a estas questões ainda junta-se o fato da falta de documentação, registros importantes que muitas vezes passam despercebidos ou estão dissociados das obras e até mesmo registros trocados. O diagnóstico do estado de conservação de uma obra define a proposta de intervenção a ser realizada. Muitas vezes são necessários exames com extração de amostras, porém nem sempre isto é possível, pois falamos de obras históricas. Os metais diferentes ou mesmo metais constituídos por 
fases diferentes não devem necessariamente ser tratados ou conservados da mesma maneira e o fato de objetos metálicos serem constituídos por ligas representa um grande desafio para sua conservação ( COSTA, 2008, p.39).

Nas sete esculturas em bronze da Praça Coronel Pedro Osório, foram observadas patologias decorrentes de fenômenos que correspondem aos "naturais", ou seja, de origem climática como oscilação da umidade relativa do ar, vegetação ao entorno, dejetos animais, chuva ácida, atmosfera poluída por gases ( típico do centro das cidades). Também observou-se a grande incidência de furtos e depredações causadas por vandalismo, ou seja, ações que não comportam justificativa. Em virtude destes fenômenos, foram observadas manchas e escorridos, colorações diferentes, partes faltantes, dissociação de partes, infiltrações nos pedestais e muitas sujidades generalizadas.

Diante, da observação do estado de conservação destas obras, conclui-se que quanto mais este conjunto que elenca o patrimônio pelotense ficar à mercê do desprezo, sem uma conservação e manutenção periódicas, estará sujeito à degradação acelerada.

\section{REFERÊNCIAS}

ALEX, Sun. Projeto da Praça. Convívio e exclusão no espaço público. $2^{\text {a }}$ Ed.- São Paulo: Editora Senac São Paulo, 2011. 292p.

ASSMANN, Aleida. Espaços da recordação. Formas e transformações da memória cultural. Tradução: Paulo Soethe. Campinas, SP: Editora Unicamp, 2011.456p.

ASKELAND, Donald, R. Ciência e Engenharia dos Materiais. Tradução Vertice Translate e All Tasks. São Paulo: Cengage Learning, 2008.

CALDAS,V., Karen. Reversilidade ou Retratabilidade? Discutindo o critério da Teoria da Conservação - Restauração em Cesari Brandi e Salvador Muñoz Viñas. 2011 Monografia (requisito parcial para título de Bacharel em Conservação e Restauro) - Universidade Federal de Pelotas, RS - UFPel.

COSTA, Virginia. Ligas Metálicas: estrutura, propriedades e conservação de objetos culturais. Memória e Patrimônio: ensaios sobre a diversidade cultura. MICHELON, F. Ferreira; TAVARES, F. Silveira; Mestrado em Memória Social e Patrimônio Cultural/ UFPel.- Pelotas: Editora da UFPel, 2008. 240. Il.p\&b. 
DVORÁK, Max. Catecismo da preservação de monumentos. Tradução Valéria Alves Esteves Lima; apresentação Valéria Alves Esteves Lima, Jens Baugartem, Beatriz Mugayar Kühl.- São Paulo: Ateliê Editorial, 2008.

LOPES, D. Simões. Reestruturação da Praça Cel. Pedro Osório como um conjunto urbano. Monografia apresentada no programa de Pós- graduação em Artes, como requisito parcial para obtenção do título em Especialista em Patrimônio Cultural: Conservação de artefatos, sob a orientação da professora mestre Carmem Lucia Abadie Biasoli ( 2005 70p.).

MAGAlHÃES, M. Osório. História e Tradições da cidade de Pelotas. $6^{\text {a }}$ Ed. ver. e ampl. - Porto Alegre: ardotempo, 2011.

MARTÍNEZ, S. Díaz; ALONSO, E. García. Técnicas metodológicas aplicadas a la conservación-restauración del patrimônio metálico. Ministério de Cultura. Dirección General de Bellas Artes y Bienes Culturales; Subdirección General del Institudo del Patriminio Cultural del España. 2011.

MONQUElat, A. Fernando. As Praças de Pelotas e suas histórias (Século XIX). Pelotas: Mundial, 2015. 284p.

MUTZENBERG, Lenice, Lucia. A Escultura pública de Antonio Caringi em Pelotas.Monografia apresentada ao Curso de Pós- Graduação em Artes- Especialização em Patrimônio Cultural: Conservação de Artefatos do Instituto de Artes e Design da Universidade Federal de Pelotas, como requisito parcial à obtenção de titulo de Especialista em Patrimônio Cultural: Conservação de Artefatos. 2006.

PAIXÃO, Antonina. A escultura de Antonio Caringi. Conhecimento, técnica e arte. Pelotas: Ed. UFPel, 1988.

READ, H. Edward. Escultura moderna: uma história concisa; tradução Ana Aguiar Cotrim, - São Paulo: Martins Fontes, 2003,- (Coleção a).

XAVIER, J. Silva. Chafarizes e Caixa D’Água de Pelotas : Elementos de modernidade do primeiro sistema de abastecimento (1871). Monografia apresentada ao curso de Pós Graduação em Artes - Patrimônio Cultural e Conservação de Artefatos do Instituto de Artes e Design da Universidade Federal de Pelotas, como requisito parcial para obtenção do título de Especialista em Artes. 